\title{
Zero-trans fats designed by enzyme-catalyzed interesterification of rice bran oil and fully hydrogenated rice bran oil
}

\author{
Nicolás Callejas Campioni ${ }^{1}$ (D) Leopoldo Suescun Pereyra $^{2}$ (D), Ana Paula Badan Ribeiro ${ }^{3}$ \\ and Iván Jachmanián Alpuy ${ }^{1, *}$ (i) \\ ${ }^{1}$ Fats and Oils Area, Department of Food Science and Technology, Facultad de Química, Universidad de la República (UDELAR), Av. \\ Gral. Flores 2124, 11800 Montevideo, Uruguay \\ ${ }^{2}$ Laboratorio de Cristalografía (Crysmat-Lab), Facultad de Química, Universidad de la República (UDELAR), Av. Gral. Flores 2124, \\ 11800 Montevideo, Uruguay \\ ${ }^{3}$ Food Technology Department, Faculty of Food Engineering, State University of Campinas - UNICAMP, C.P. 6041, 13083-970 \\ Campinas, SP, Brazil
}

Received 2 July 2021 - Accepted 20 September 2021

\begin{abstract}
Zero-trans edible fats attractive to be used for shortenings or margarines were designed solely from rice bran oil (RBO). For this purpose, RBO was fully hydrogenated, blended with the original oil at different percentages, and finally, blends were interesterified by an enzyme-catalyzed process. The interesterification process reduced the concentration of trisaturated and triunsaturated triglycerides and increased the concentration of medium saturation degree molecules, thus increasing their compatibility and causing the moderation of the melting point, as compared with blends. Conversely to blends, products showed a high tendency to crystallize under the $\beta^{\prime}$ polymorph, which is the preferred one for products destined for many edible applications. Results demonstrated that the proper combination of different technologies (total hydrogenation, blending and interesterification) is a versatile and useful technology for designing zero-trans fats from RBO, attractive for the confection of shortenings or margarines for different applications depending on the proportion of each component in the starting blend. This strategy offers an attractive alternative for the diversification of RBO utilization, a valuable vegetable oil still underexploited, providing attractive fats useful for structuring different type of foods.
\end{abstract}

Keywords: rice bran oil / enzyme-catalyzed interesterification / total hydrogenation / margarines / shortenings

Résumé - Graisses zéro-trans conçues par inter-estérification enzymatique de mélanges d'huiles de son de riz native et totalement hydrogénée. Des graisses alimentaires zéro-trans pouvant être utilisées comme matière grasse ou dans des margarines ont été élaborées uniquement à partir d'huile de son de riz (RBO). Ainsi, une huile de son de riz a été totalement hydrogénée, puis mélangée dans différentes proportions à l'huile de départ, et finalement, les mélanges ont été inter-estérifiés par voie enzymatique. Le processus d'inter-estérification a réduit la concentration en triglycérides homogènes (saturés et insaturés) et a accru la concentration en molécules de degré de saturation moyen, améliorant ainsi leur compatibilité et modérant le point de fusion, par rapport aux mélanges. À l'inverse des mélanges, les produits ont montré une forte tendance à cristalliser en polymorphe $\beta$, , le plus adapté aux produits destinés à de nombreuses applications alimentaires. Les résultats ont démontré que la combinaison adéquate de différentes technologies (hydrogénation totale, mélange et inter-estérification) représente une solution polyvalente et utile pour fabriquer des graisses zéro-trans à partir de $\mathrm{RBO}$, intéressantes pour la confection de matières grasses ou de margarines, et ce pour diverses applications selon la proportion de chaque composant dans le mélange de départ. Cette stratégie offre une alternative intéressante pour la diversification de l'utilisation de l'huile de son de riz, une huile végétale précieuse encore sous-exploitée, en fournissant des graisses intéressantes et utiles pour structurer différents types d'aliments.

Mots clés : huile de son de riz / inter-estérification enzymatique / hydrogénation totale / margarines / matières grasses

*Correspondence: ijachman@fq. edu.uy 


\section{Introduction}

Several nutritional studies have demonstrated the direct relationship between the intake of trans fatty acids (TFA) and the increase in the serum levels of low-density lipoproteins (LDL) and the decrease of high-density lipoproteins (HDL), thus notably increasing the risk of suffering cholesterol risk of cardiovascular diseases (Oteng and Kersten, 2020).

Considering this problem, the World Health Organization has recently launched the REPLACE program, which involves an action package providing a strategic approach to eliminating industrially produced TFA from national food supplies, with the goal of global elimination by 2023 (WHO, 2018).

Although undoubtedly such a program is necessary, it involves a significant challenge for the food industry. Under this scenario, the interesterification of blends of fats from different origins, which has been a convenient and versatile method for designing zero-trans edible fats, could offer an alternative technology (Kodali, 2005). Such technology usually involves the blending of liquid oil with fat that provides saturated fatty acids to the blend, responsible for conferring consistency to the interesterified product (Ribeiro et al., 2009; Segura et al., 2011).

Saturated fats from different origin have been successfully used for such purpose, like palm oil (Danthine et al., 2014), palm stearin (Jennings and Akoh, 2010), beef tallow (Segura et al., 2011), or some fully hydrogenated oils (Kloek et al., 2000; Pacheco et al., 2013; Ribeiro et al., 2009). Unlike partially hydrogenated oils, the latter does not contain trans fatty acid as long as the process is efficiently continued until completion. Thus, fully hydrogenated oils are attractive raw materials to be used as the hard component of the blends to be interesterified, as mentioned above and reported by other researchers in the several following publications. The chemical interesterification of soybean oil with fully hydrogenated soybean oil was proposed to produce zero-trans fats suitable for different types of shortenings, depending on the ratio of each component in the blend (Ribeiro et al., 2009).

More recently, a low trans margarine fat analogue to beef tallow was achieved by blending fully hydrogenated palm oil with soybean oil in a ratio $3: 4$ and processing the blend by lipase-catalyzed interesterification. Product properties were highly improved as compared with the starting blend, showing high potential in formulating a low trans fat margarine (Li et al., 2018).

Among much work done exploring different alternatives for applying this technology, previous work regarding the use of rice bran oil (RBO) as the main raw material is very scarce (Segura and Jachmanián, 2020). However, RBO has several advantages due to its fatty acid composition as well as its nutritional properties. It is well known that RBO consumption has beneficial effects on human health, causing a cholesterollowering effect and a reduction in aortic fatty streaks (Chandrashekar et al., 2014). Additionally, it was determined that the amount of cholesterol-lowering occurs to a greater extent than expected from the fatty acid composition of the oil, suggesting that other components in the oil were responsible for this effect ( $\mathrm{Xu}$ et al., 2001). The major components of vitamin $\mathrm{E}$ in rice bran are $\alpha$-tocopherol, $\alpha$-tocotrienol, $\gamma$-tocopherol and $\gamma$-tocotrienol. RBO also possesses about
$3000 \mathrm{mg} / \mathrm{kg}$ of oryzanols, a family of 10 ferulate esters of triterpene alcohol ( $\mathrm{Xu}$ et al., 2001) reported possessing the capability of lowering cholesterol levels in serum (Chandrashekar et al., 2014; Chung and Kang, 2020). Oryzanols components have too antioxidant functions because their structure includes ferulic acid, a potent antioxidant (Liu et al., 2021). Despite having good nutritional composition and providing health benefits to humans, whereby it has been considered one of the most nutritious and functional oils in nature, RBO is still underutilized (Oi-Ming et al., 2019).

Concerning the fatty acid composition of RBO, it has about $20 \%$ palmitic acid (Firestone, 2006), a sixteen-carbon chain length fatty acid that confers some heterogeneity to triacylglycerols (TAG) structure. It has been widely observed that the $\beta$ ' polymorphic form, required in fats destined to shortenings or margarines, is promoted by fats whose TAG contains different kinds of fatty acid moieties (Sato, 2001).

Considering those particular characteristics of RBO, in this work, we propose the blending of this oil at different proportions with fully hydrogenated rice bran oil (FHRBO), followed by the enzyme-catalyzed interesterification of the blend, for the obtention of zero-trans fats rich in the native bioactive compounds of RBO and with improved crystallization properties, thus attractive to be destined to the confection of zero-trans margarine and shortenings.

Enzymes, as naturally occurring biocatalysts, play an increasing role in developing green processes and environmentally benign production technology, particularly for food, as it holds a great promise to enable some processes under mild conditions that chemical catalysts cannot do (Feltes et al., 2012; Pacheco et al., 2013). Thus, considering those advantages, a lipase-catalyzed process was chosen for this work, considering that the milder reaction conditions required would help to preserve the valuable bioactive compounds from RBO (Segura and Jachmanián, 2020; Zhang et al., 2021). Additionally, it is expected that bioprocessing will be applied much more extensively in RBO processing in the future as the development of enzyme techniques and the popularization of RBO progress (Jiang, 2019). Thus, this work proposes an attractive alternative to contribute in this direction.

\section{Materials and methods}

Refined rice bran oil (ARROZUR SA, Treinta y Tres, Uruguay) was acquired in the local market. Lipase from porcine pancreas was supplied by Sigma-Aldrich (PPL type II, activity equal to $11.6 \mathrm{U} / \mathrm{mg}$, in $\mu \mathrm{mol}$ of fatty acids hydrolyzed per minute per mg lipase). Lipozyme TL IM (from Thermomyces lanuginosus) was kindly provided by Novozymes, Denmark.

Organic solvents, analytical standards and reagents were supplied by Dexin S.R.L, Montevideo, Uruguay (representative of Sigma-Aldrich Company).

\subsection{Hydrogenation}

Hydrogenation of RBO was performed in a high pressure/ high temperature $250 \mathrm{~mL}$ reactor $(4570 \mathrm{HP} / \mathrm{HT}$ Parr Instrument Company, Illinois, USA). The reactor was equipped with a mechanical gas entrainment stirrer to favour 
gas/liquid mass transfer phenomena, a $500 \mathrm{~mL}$ burette for controlling the amount of $\mathrm{H}_{2}$ provided to the reactor, a heating jacket, pressure and temperature transducers and a Parr 4848 Reactor Controller. Reactions were performed under $\mathrm{H}_{2}$ at 15 bar and $120^{\circ} \mathrm{C}$, using $5 \% \mathrm{Ni} / \mathrm{SiO}_{2}$ catalyst (Pricat 9910, from Johnson Matthey, London, UK). After a reaction period of 3 hours, FHRBO was achieved, as verified by the analysis of the product by gas chromatography (GC), as described below. Finally, the product was recovered from the reactor and filtered inside an oven at $70^{\circ} \mathrm{C}$ by passing through a filter paper (Whatman grade 5) to remove the catalyst, and stored until used.

\subsection{Preparation of blends}

Nine blends of RBO with 10 to $90 \%$ FHRBO (with $10 \%$ increments) were prepared by weighing the corresponding amount of each fat inside $15 \mathrm{~mL}$ screw cup vials to totalize about $10 \mathrm{~g}$ of the blend. Vials were subjected to a stream of nitrogen, hermetically closed and located inside an orbital shaker (Lab Companion, model SI-600) at $70^{\circ} \mathrm{C}$ and $200 \mathrm{rpm}$ during $15 \mathrm{~min}$, for complete homogenization.

\subsection{Interesterification reactions}

Interesterification reaction was performed on pure $\mathrm{RBO}$, or RBO blended with FHRBO. $7 \mathrm{~g}$ of the substrate was transferred to a screw cap tube, and $0.7 \mathrm{~g}$ of Lipozyme TL IM (previously dried under a vacuum at $60^{\circ} \mathrm{C}$ for $30 \mathrm{~min}$ ) were added. The tube was subjected to a stream of nitrogen, closed and placed inside the orbital shaker at $60^{\circ} \mathrm{C}$, shaker speed was set to $200 \mathrm{rpm}$ and incubation prolonged for $24 \mathrm{~h}$. After the incubation period, the enzyme was separated from products by filtration inside an oven at $70{ }^{\circ} \mathrm{C}$ and the lipid fraction kept under nitrogen at $-20^{\circ} \mathrm{C}$ until analyzed. This procedure was performed in duplicate and the products destined for independent analysis.

\subsection{Fatty acid composition}

Samples were treated with $\mathrm{BF}_{3} / \mathrm{MeOH}$ (boron trifluoride solution in methanol) according to the AOCS method Ce 1b-89 (AOCS, 2017) to convert the triacylglycerols to the corresponding methyl esters. The esters were analyzed by GC, using an equipment Shimadzu GC-2010, equipped with FID and a capillary column Supelco SP2560 $(100 \mathrm{~m} \times 0.25 \mathrm{~mm} \times 0.20 \mu \mathrm{m})$. The temperature program started at $175^{\circ} \mathrm{C}$, followed by a heating step $\left(5^{\circ} \mathrm{C} / \mathrm{min}\right)$ to $220^{\circ} \mathrm{C}$, and remained at $220^{\circ} \mathrm{C}$ for $60 \mathrm{~min}$. Nitrogen at $150 \mathrm{kPa}$ at column head was used as the carrier gas, with a split ratio 1:80. Fatty acid composition was determined in duplicate, and average results reported. The identification of the compounds was accomplished by comparing the retention times with that corresponding to the analysis of fatty acids methyl esters standards (provided by Sigma-Aldrich) under identical conditions.

\subsection{Triacylglycerol (TAG) composition}

The separation and quantitative determination of the triglycerides were performed using high-performance liquid chromatography (HPLC) following the procedure described below, based on the AOCS Official Method Ce 5b-89 (AOCS, 2017). Samples were dissolved in acetone $(5 \mathrm{mg} / \mathrm{mL})$ and directly analyzed using an HPLC Shimadzu Prominence 20A (Shimadzu, Corporation, Kyoto, Japan), equipped with an evaporative light scattering detector Shimadzu ELSD-LTII, two columns Supelcosil TM C18 $(25 \mathrm{~cm} \times 4.6 \mathrm{~mm} \times 5 \mu \mathrm{m})$. The analysis started delivering a flow rate of $1 \mathrm{~mL} / \mathrm{min}$ of the mixture acetone/acetonitrile 50:50, followed by an increasing linear gradient of chloroform to achieve the ratio acetone/ acetonitrile/chloroform 40:40:20 at $60 \mathrm{~min}$. The solvent composition remained constant for $20 \mathrm{~min}$, and finally returned to the starting composition at $85 \mathrm{~min}$. Peaks were identified using pure TAG standards and considering the order of elution according to the equivalent carbon number (ECN). Two replicate analyses were performed, and the average values were reported.

\subsection{Analysis of fatty acid composition at the sn-2 position}

The nature of fatty acids in the $s n-2$ position of triacylglycerols was determined by hydrolysis with porcine pancreas lipase (PPL), according to the AOCS method Ch 3-91 (AOCS, 1997). The method involves the hydrolysis of oil with the sn-1,3-specific PPL, followed by the purification of the 2-monoacylglycerols (2-MAG) produced by thin-layer chromatography. The 2-MAG band is scrapped off, submitted to a derivatization reaction to methyl esters, and analyzed by GC. Two replicate analyses were performed, and average values reported.

\subsection{Thermal behavior}

Melting thermograms were determined by differential scanning calorimetry (DSC), using a calorimeter TA Q20 (TA Instruments), equipped with a refrigerated cooling system RCS90. The temperature was programmed according to the AOCS method Cj 1-94 (AOCS, 2017), which involves initial heating to $90^{\circ} \mathrm{C}$ for the complete melting of the sample, followed by cooling at $10^{\circ} \mathrm{C} / \mathrm{min}$ to $-60^{\circ} \mathrm{C}$, a tempering at $-60{ }^{\circ} \mathrm{C}$ for $30 \mathrm{~min}$, and a final heating step at $5^{\circ} \mathrm{C} / \mathrm{min}$ until complete melting. Data processing was performed using TA Universal Analysis 2000 software (version 3.9A). A high purity standard of metallic Indium provided by DSC manufacturer was used for the calibration of the equipment. Two replicate analyses were performed, and the average values reported.

\subsection{Solid fat content (SFC)}

The solid fat content was determined using a nuclear magnetic resonance ( $\mathrm{p}-\mathrm{NMR}$ ) spectrometer (Bruker Minispec PC120) and a TCON 2000 high precision dry bath $\left(0-70^{\circ} \mathrm{C}\right)$ (Duratech, USA), according to the AOCS method Cd 16b-93 (AOCS, 2017). Sample readings were taken in series at $5^{\circ} \mathrm{C}$ increments in the temperature range of $10-65^{\circ} \mathrm{C}$.

\subsection{Polymorphism analysis}

The polymorphic forms were determined by X-ray diffraction spectroscopy according to the AOCS method $\mathrm{Cj}$ 2-9593 (AOCS, 2017). Samples were completely melted and 
spread over the glass X-ray slide and kept at the temperature to be analyzed $\left(20^{\circ} \mathrm{C}\right)$ for $24 \mathrm{~h}$ before the analysis. A Rigaku ULTIMA IV (Rigaku Corporation, Tokyo, Japan) theta-theta powder X-ray diffractometer with a copper X-ray tube was used for the analysis $(\mathrm{Cu}-\mathrm{K} \alpha, \lambda=1.5406 \AA)$. Polymorphic forms were determined according to diffraction patterns in the short spacing region, scanned from 10 to $30^{\circ}$ at $0.04^{\circ}$ steps with a rate of $10 \mathrm{~s}$ by step.

\subsection{Statistical analysis}

Data were subjected to variance analysis (ANOVA) using the statistical analysis software InfoStat, version 2020 (Di Rienzo et al., 2020). Significant differences between mean values were compared with a Tukey's test with a confidence interval of $95 \%(P<0.05)$.

\section{Results and discussion}

\subsection{Fatty acid composition}

Table 1 shows the fatty acid composition of both raw materials (RBO and FHRBO). Oleic acid is the major fatty acid in RBO (43.5\%), followed by linoleic (32.7\%) and palmitic acid $(18.6 \%)$. This composition is in agrees with that previously reported (Mayamol et al., 2009; Zhang et al., 2021). As expected, major fatty acids in FHRBO were palmitic and stearic acids, at concentrations equal to that of C16:0 and to the total of all $\mathrm{C} 18$ fatty acids in the original $\mathrm{RBO}$, respectively. Additionally, minor saturated fatty acids were identified at similar percentages than in the starting RBO.

Neither cis nor trans unsaturated fatty acids remained in FHRBO, confirming that the full hydrogenation was effectively achieved. The absence of trans fatty acids is of significant interest from a nutritional point of view since, as mentioned, this work was focused on the design of zero-trans edible fats.

\subsection{Triacylglycerol composition}

Figure 1a, b shows the HPLC chromatograms of RBO and FHRBO, respectively. As it can be observed, the analytical method permitted a convenient separation of TAG molecules and, due to the absence of trisaturated TAG in RBO, there were no coincidences in the retention time of the peaks in the chromatograms of both raw materials, which simplified the analysis of blends and products.

Table 2 shows the TAG composition of RBO and FHRBO, their blends $(\mathrm{B})$ in different proportions and the products $(\mathrm{P})$ obtained by the interesterification of the blends during $24 \mathrm{~h}$ using Lipozyme TL IM as catalyst.

RBO was mostly composed by two types of TAG molecules: $45.5 \%$ triunsaturated TAG with 54 carbons (LOO, LLO, OOO and LLL) and 42.9\% monosaturated diunsaturated 52 carbons TAG (thus, containing one molecule of palmitic acid: POO, PLO, and PLL), and a minor proportion of disaturated monounsaturated TAG (PPL and PPO). These results are in good agreement with that reported for rice bran oils from different varieties by Zhang et al. (2021).
Table 1. Fatty acid composition of rice bran oil (RBO) and fully hydrogenated rice bran oil (FHRBO).

\begin{tabular}{lcl}
\hline Fatty acid & RBO & FHRBO \\
\hline C 14:0 (myristic) & $0.20 \pm 0.01$ & $0.20 \pm 0.02$ \\
C 16:0 (palmitic) & $18.6 \pm 0.3$ & $18.8 \pm 0.9$ \\
C 18:0 (stearic) & $1.4 \pm 0.2$ & $79.0 \pm 0.9$ \\
C 18:1 (oleic) & $43.5 \pm 0.1$ & $n d$ \\
C 18:2 (linoleic) & $32.7 \pm 0.5$ & $n d$ \\
C 18:3 (linolenic) & $0.8 \pm 0.1$ & $n d$ \\
C 20:0 (arachidic) & $0.40 \pm 0.03$ & $1.10 \pm 0.01$ \\
C 22:0 (behenic) & $0.10 \pm 0.01$ & $0.30 \pm 0.08$ \\
C 24:0 (lignoceric) & $0.30 \pm 0.01$ & $0.40 \pm 0.07$ \\
SFA & $21.0 \pm 0.1$ & $99.8 \pm 0.2$ \\
MUFA & $77.0 \pm 0.1$ & $n d$ \\
PUFA & $33.5 \pm 0.6$ & $n d$ \\
\hline
\end{tabular}

SFA: saturated fatty acids; MUFA: monounsaturated fatty acids; PUFA: polyunsaturated fatty acids; $n d$ : non-detectable.
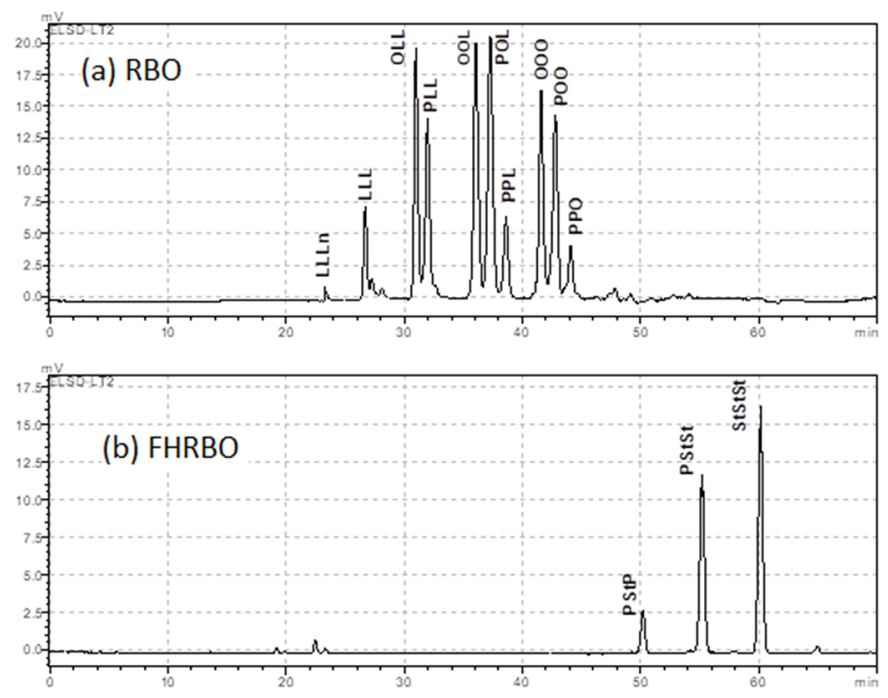

Fig. 1. Chromatograms corresponding to triacylglycerol composition by HPLC of rice bran oil (RBO) (a) and the fully hydrogenated rice bran oil (FHRBO) (b).

Accordingly, StStSt represented near half of the total FHRBO triacylglycerols $(50.6 \%)$, while PStSt and PStP concentrations were $38.8 \%$ and $9.9 \%$, respectively. The relatively high percentage of palmitic acid in the original RBO confers to FHRBO a relative highly heterogeneous TAG composition, which can be determinant on the crystallization behaviour. It is well known that TAG heterogeneity could favour the crystallization of polymorph $\beta$, which is the preferred one for fats destined to shortenings or margarines. TAG heterogeneity of FHRBO is higher than that of other widely used hydrogenated oils, like the known $\beta$-tending fully hydrogenated soybean oil, with $63.4 \%$ StStSt and $30.8 \%$ PStSt (Ribeiro et al., 2009). Conversely, FHRBO heterogeneity is close to the $\beta$ '-tending fully hydrogenated cottonseed oil, with $40 \% \mathrm{StStSt}$ and $43 \%$ PStSt as the major triacylglycerols (Shi et al., 2005). 
Table 2. Triacylglycerol composition of rice bran oil (RBO), fully hydrogenated rice bran oil (FHRBO), their blends, and their interesterification products (minor TAG with concentrations under $1 \%$ in all samples were not shown).

\begin{tabular}{|c|c|c|c|c|c|c|c|c|c|c|c|c|c|c|c|c|c|c|c|c|c|}
\hline \multirow[t]{2}{*}{ TAG } & \multirow[t]{2}{*}{ FHRBO } & \multicolumn{20}{|c|}{ FHRBO (wt.\%) } \\
\hline & & $\bar{B}$ & $\mathrm{P}$ & $\overline{\mathrm{B}}$ & $P$ & $\overline{\mathrm{B}}$ & $\mathrm{P}$ & $\overline{\mathrm{B}}$ & $\mathrm{P}$ & $\overline{\mathrm{B}}$ & $P$ & $\overline{\mathrm{B}}$ & $P$ & $\overline{\mathrm{B}}$ & $P$ & $\bar{B}$ & $\mathrm{P}$ & $\overline{\mathrm{B}}$ & $\mathrm{P}$ & $\overline{\mathrm{B}}$ & $P$ \\
\hline StStSt & 50.6 & 45.5 & 39.6 & 40.5 & 28.6 & 35.4 & 18.3 & 30.4 & 9.3 & 25.3 & 7.8 & 20.2 & 3.5 & 15.2 & 1.4 & 10.1 & 0.5 & 5.1 & $n d$ & $n d$ & $n d$ \\
\hline PStSt & 38.8 & 34.9 & 32.2 & 31.0 & 25.6 & 27.1 & 26.0 & 23.3 & 13.3 & 19.4 & 10.2 & 15.5 & 6.1 & 11.6 & 2.7 & 7.8 & 1.3 & 3.9 & 0.7 & nd & $n d$ \\
\hline StOSt & $n d$ & nd & 4.3 & nd & 9.5 & $n d$ & 10.9 & $n d$ & 11.4 & $n d$ & 11.2 & nd & 8.2 & nd & 4.8 & nd & 2.9 & $n d$ & 0.2 & $n d$ & $n d$ \\
\hline LStSt & nd & nd & 3.6 & nd & 14.0 & $n d$ & 17.1 & nd & 21.5 & nd & 18.0 & $n d$ & 16.1 & nd & 11.7 & nd & 8.8 & nd & 4.1 & nd & $n d$ \\
\hline PPO & $n d$ & 0.3 & 0.5 & 0.6 & 0.4 & 1.0 & 0.5 & 1.3 & 0.7 & 1.6 & 0.6 & 1.9 & 0.5 & 2.3 & 0.5 & 2.6 & 0.5 & 2.9 & 0.4 & 3.2 & 3.4 \\
\hline POO & $n d$ & 1.3 & $n d$ & 2.5 & $n d$ & 3.8 & $n d$ & 5.0 & $n d$ & 6.3 & $n d$ & 7.5 & $n d$ & 8.8 & $n d$ & 10.1 & $n d$ & 11.3 & $n d$ & 12.6 & 11.1 \\
\hline LOSt & $n d$ & $n d$ & 0.4 & $n d$ & 1.5 & $n d$ & 3.7 & $n d$ & 9.2 & $n d$ & 11.3 & $n d$ & 14.9 & $n d$ & 24.2 & $n d$ & 16.9 & nd & 15.1 & $n d$ & $n d$ \\
\hline LStP & $n d$ & $n d$ & 1.9 & $n d$ & 4.8 & $n d$ & 6.8 & $n d$ & 11.2 & $n d$ & 11.3 & $n d$ & 11.9 & $n d$ & 11.3 & $n d$ & 9.5 & $n d$ & 7.1 & $n d$ & $n d$ \\
\hline OOO & nd & 1.2 & $n d$ & 2.4 & $n d$ & 3.6 & $n d$ & 4.8 & 0.3 & 6.0 & 0.9 & 7.1 & 1.7 & 8.3 & $n d$ & 9.5 & 3.9 & 10.7 & 5.9 & 11.9 & 7.7 \\
\hline PLL & $n d$ & 1.1 & $n d$ & 2.2 & $n d$ & 3.4 & 0.2 & 4.5 & 0.7 & 5.6 & 1.6 & 6.7 & 3.1 & 7.8 & 4.9 & 8.9 & 5.7 & 10.1 & 7.9 & 11.2 & 8.8 \\
\hline LLO & $n d$ & 1.3 & $n d$ & 2.6 & $n d$ & 3.9 & $n d$ & 5.2 & 0.6 & 6.5 & 1.5 & 7.8 & 2.8 & 9.1 & 5.1 & 10.4 & 7.9 & 11.7 & 12.2 & 13.0 & 17.3 \\
\hline LLL & $n d$ & 0.4 & $n d$ & 0.8 & $n d$ & 1.2 & $n d$ & 1.6 & $n d$ & 2.0 & $n d$ & 2.4 & 0.4 & 2.8 & 0.7 & 3.2 & 1.9 & 3.6 & 2.8 & $n d$ & 5.0 \\
\hline
\end{tabular}

O: oleic; St: stearic; L: linoleic; P: palmitic; $n d$ : non-detectable.

Table 2 shows several changes in TAG composition between blends and their corresponding interesterification products, which confirms that the enzyme was very active in the catalysis of the interesterification process. Although results corresponding to the interesterification of pure RBO ( $0 \%$ FHRBO) are shown, pure FHRBO was not possible to be interesterified under identical conditions to the rest of the samples due to its high melting point (over the incubation temperature). In order to simplify the analysis of results, TAGs were grouped in four types (SSS: trisaturated; SSU: disaturated monounsaturated; SUU: monosaturated diunsaturated; UUU: triunsaturated) and their percentages in the blend (B) and product $(\mathrm{P})$ plotted against the rate of FHRBO in starting blend (Fig. 2).

As expected, Figure $2 \mathrm{a}$ shows that interesterification caused the diminishing in the level of SSS, provided to samples by FHRBO. Although all products showed a concentration of SSS lower than that in the starting blend, a maximal reduction from 26.5 to $31.0 \%$ occurred in mixtures containing from 40 to $60 \%$ FHRBO, respectively. Additionally, the concentration of UUU triglycerides from RBO (mostly OOO, LOO, LLO, LLL) diminished too as a consequence of the interesterification process (Fig. 2d), and this group of TAG completely disappeared in those products from blends containing more than $60 \%$ FHRBO.

As a result of the diminishing in the concentration of SSS and UUU triglycerides from blends to products, the concentrations of TAG comprised of both saturated and unsaturated fatty acids increased after the interesterification process. Figure $2 b$ shows that the concentration of SSU triglycerides drastically increased in all samples, achieving a maximum of $46.0 \%$ in the product from the blend containing 60\% FHRBO (with a starting SSU concentration of only 3.4\%). This result is mainly a consequence of the appearance of three new TAG species that were not present in any of the starting materials: StOSt, LStSt and LStP (Tab. 2).

The concentration of SUU triacylglycerides showed a different tendency according to FHRBO percentage (Fig. 2c), while their concentration increased in that samples with less than $60 \%$ FHRBO, it decreased in the rest of the samples. Changes in the concentration of this group of TAG can be attributed to the occurrence of two opposite effects: while new TAG like StOO and LOSt were formed, POO from FHRBO completely disappeared after the incubation. Additionally, PLO and PLL diminished in different extent depending on the percentage of FHRBO in the blend.

The reduction of SSS and UUU triglycerides, characteristics from both components of the blends, and the increment in the concentration of TAG with a medium saturation degree, suggests that products should be composed by a blend of TAG species with higher compatibility than the starting blends. The increased concentration of SSU and SUU triacylglycerols promoted by interesterification has been associated with enhanced technological functionality and improved plasticity, thus with higher potential for food applications (Ribeiro et al., 2009). Additionally, it is well known that intermediate melting point triacylglycerides SSU type, which showed the higher increment after interesterification (Fig. 2b), have been associated with a higher oil binding capacity due to their intermediate polarity, allowing them to act as bridges between high-melting TAG and liquid oil, thus playing an essential role in improving the plasticity of fats (Jahaniaval et al., 2002).

\subsection{Fatty acid regiodistribution}

The HPLC analytical method used in TAG analysis is relatively efficient for the separation of the different TAG by 


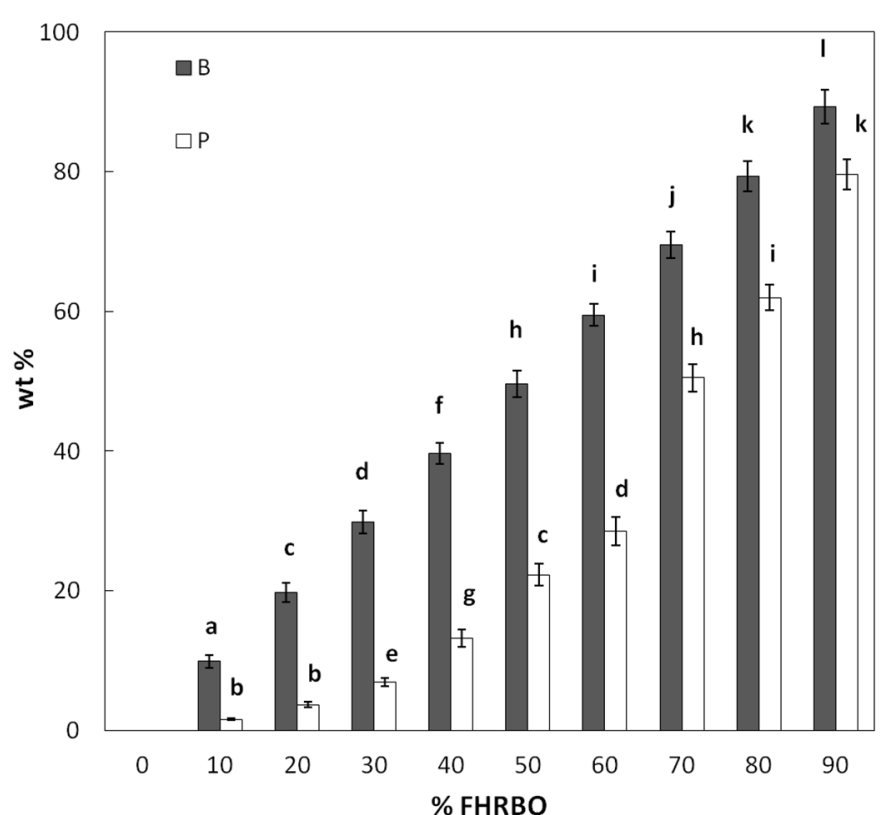

(a)

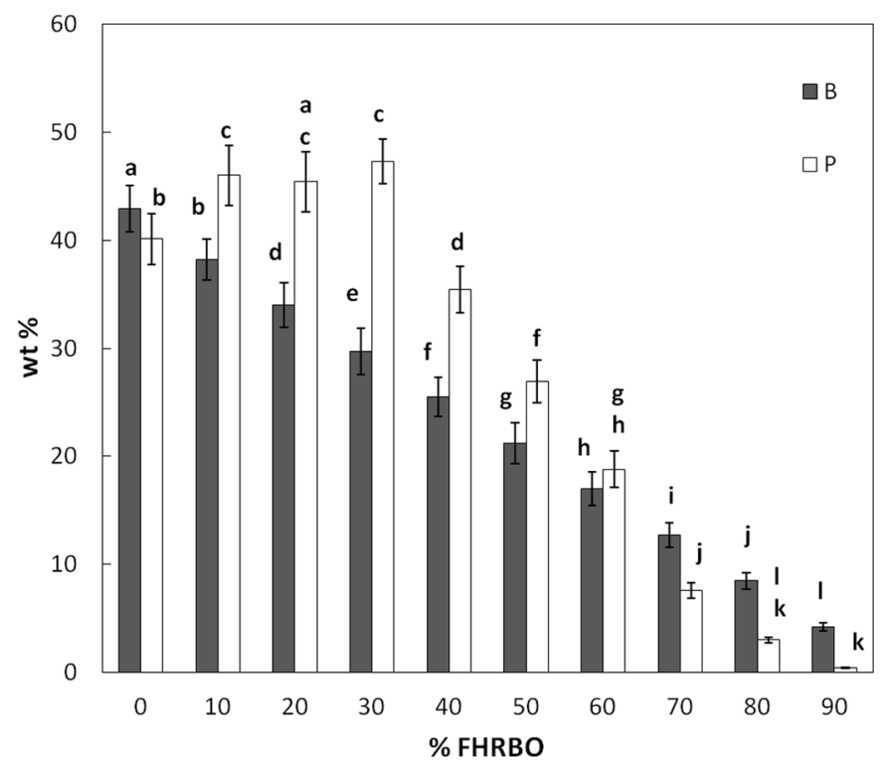

(c)

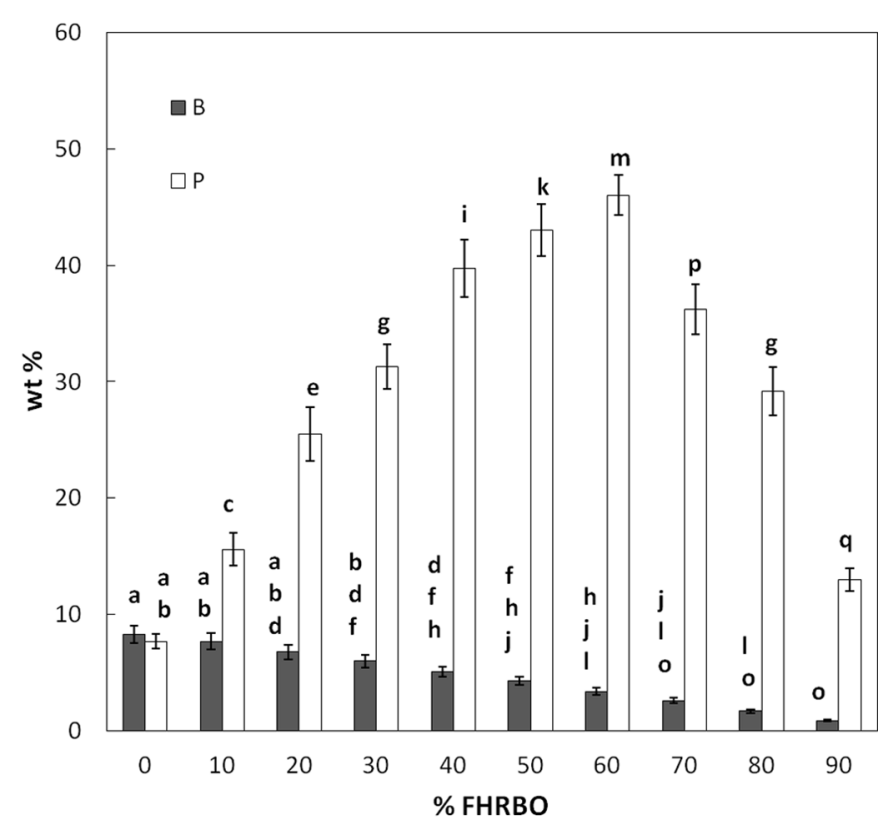

(b)

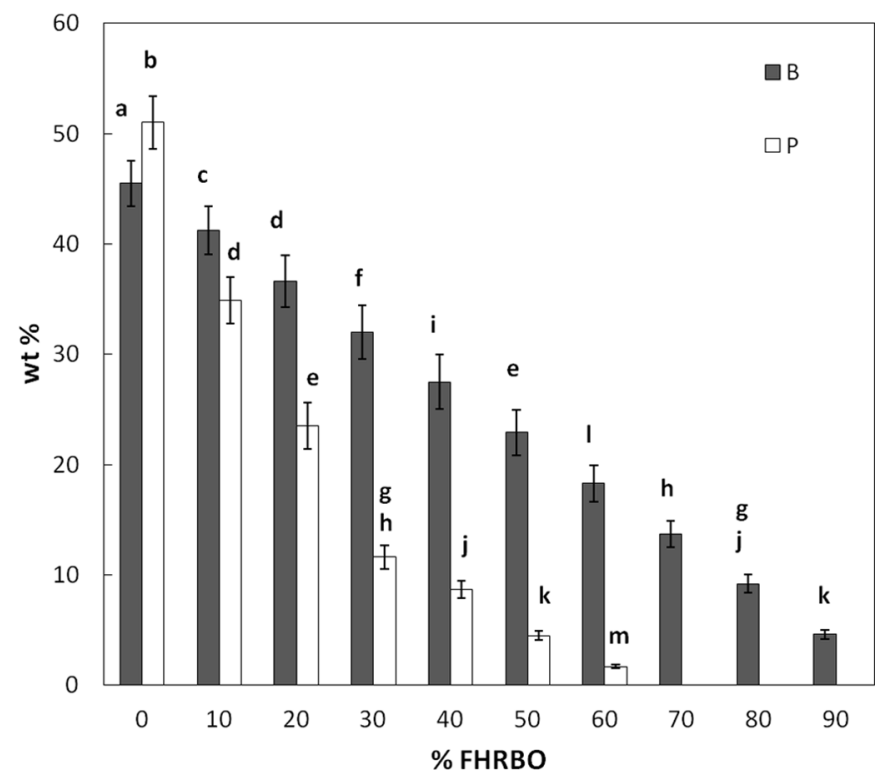

(d)

Fig. 2. Composition in type of TAGs of the blends RBO/FHRBO "B" with different percentage of FHRBO and their interesterification products "P"; SSS: triunsaturated TAG (a); SSU: disaturated monounsaturated TAG (b); SUU: monosaturated diunsaturated TAG (c); UUU: triunsaturated TAG (d). The difference between percentages is statistically significant $(P<0.05)$ if bars have different letters.

ECN parameter, as shown in Table 2, but does not discriminate among TAG isomers. Thus, the regiodistribution of the fatty acids cannot be determined by this method.

In order to provide additional information about TAG structure and the distribution of the fatty acids in the glycerol backbone, which is of major interest in determining the properties of these materials, the method of hydrolysis with porcine pancreas lipase (PPL) was performed. Results showed that only $3.1 \%$ of $s n-2$ position of RBO triglycerides was occupied by palmitic fatty acid (Tab. 3), suggesting that PStSt and PStP should be the major structures of the heterogeneous TAG from FHRBO. These two heterogeneous TAGs are of major interest because they are known to have a preference to crystallize in the $\beta$ ' form (Timms, 2003), which is the preferred polymorphic form for fats destined to shortenings and margarines. As shown in Table 2, both PStSt + PStP could represent near half of the total TAG molecules of FHRBO, suggesting that this material could show a high tendency to crystallize in the $\beta$ ' form.

\subsection{Thermal analysis}

Figure 3a shows the melting thermograms obtained by DSC analysis of RBO and FHRBO and their blends at different 
Table 3. Fatty acid composition of $s n-2$ position of rice bran oil (RBO) triacylglycerols.

\begin{tabular}{ll}
\hline Fatty acid & $s n-2$ of RBO (\%) \\
\hline C 14:0 & $n d$ \\
C 16:0 & $3.1 \pm 0.6$ \\
C 18:0 & $0.9 \pm 0.2$ \\
C 18:1 & $47.3 \pm 0.6$ \\
C 18:2 & $46.0 \pm 0.7$ \\
C 18:3 & $0.7 \pm 0.2$ \\
C 20:0 & $n d$ \\
C 22:0 & $n d$ \\
C 24:0 & $n d$ \\
\hline
\end{tabular}

nd: non-detectable.

proportions. Some parameters of interest determined from thermograms are shown in Table 4. Pure FHRBO shows a single endothermic peak with a maximum at $62.7^{\circ} \mathrm{C}$, corresponding to the melting of the three trisaturated TAG present in this sample. Although each TAG from FHRBO do not have the same melting point, the presence of a single peak suggests that due to the combination of melting and solubilization phenomena, these TAG cannot be differentiated as single peaks by this thermal analysis.

Pure RBO (B-0) showed two melting peaks, the highest one at $-19.8^{\circ} \mathrm{C}$ and the smaller one at $-10.3^{\circ} \mathrm{C}$. As expected from the fatty acid composition of $\mathrm{RBO}$, it did not show any melting peak at temperatures over $0{ }^{\circ} \mathrm{C}$ (Fig. 3a). Thus, RBO will remain liquid over $0^{\circ} \mathrm{C}$, playing a role of "solvent" when blended with the high melting point of FHRBO.

Concerning the thermal behaviour of the blends, Figure $3 \mathrm{a}$ shows that they combine properties from both components. As the percentage of FHRBO decreased, the height and area of the high temperature melting peak showed by pure FHRBO decreased too, due to the progressive dilution of its trisaturated TAG. Additionally, the completion melting temperature of blends $\left(\mathrm{T}_{\mathrm{C}, \mathrm{B}}\right)$ shifted from $66.9^{\circ} \mathrm{C}$ to $55.2^{\circ} \mathrm{C}$ when the percentage of FHRBO diminished from 90 to $10 \%$, respectively (Tab. 4). The relatively high melting point of the blend containing as little as $10 \%$ of FHRBO suggests that the trisaturated TAGs from FHRBO should have a very low solubility in the liquid $\mathrm{RBO}$, thus remaining crystallized in the blend until the temperature overpasses their melting point. Similar behaviour has been reported for blends of fatty materials with low compatibility, such as soybean oil blended with fully hydrogenated soybean oil (Ribeiro et al., 2009).

It can also be observed that as the percentage of RBO increased, the peak located close to $-20^{\circ} \mathrm{C}$ gradually increased too. Thus, DSC analysis indicates that the thermal behaviour of the blends is mostly the result of the combination of the thermal behaviour of both components, expressed according to their proportion in the blend.

Figure $3 \mathrm{~b}$ shows the melting thermograms of the products obtained by interesterification of the different blends $\mathrm{RBO} / \mathrm{FHRBO}$. Concerning pure $\mathrm{RBO}$, the interesterification caused a shifting of the major peak from -19.8 to $-7.7^{\circ} \mathrm{C}$. Considering that the TAG composition of RBO was not significantly different from that of the interesterified RBO (Tab. 2), changes in the fatty acids regiodistribution could have contributed to this change of the melting thermogram.

The thermogram of the product derived from the blend containing 90\% FHRBO (P-90) shows three endothermic peaks, $P_{1}, P_{2}$ and $P_{3}$, with increasing peak temperature and area, respectively. Additionally, the thermogram has an exothermic peak $\left(P_{\mathrm{e}}\right)$ between $P_{2}$ and $P_{3}$, which evidences the occurrence of a polymorphic transition from a less to a more stable polymorph, probably from $\alpha$ to $\beta$ ' form. Considering that peak $P_{3}$ is located at a temperature range close to that of the single peak shown by the blends with a high percentage of FHRBO, it should correspond to the melting of the same group of TAG (trisaturated TAGs from FHRBO: StStSt + PStSt + PStP). This result is in agreement with the TAG composition of P-90, which has a total trisaturated TAG of $79.6 \%$ provided by FHRBO to the blend and that remained partially unreacted after the interesterification (Tab. 2). According to the diminishing of trisaturated TAG concentration in the products obtained from the blends with a lower percentage of FHRBO, $P_{3}$ area became progressively smaller. Additionally, the completion melting temperature of the products $\left(T_{\mathrm{C}, \mathrm{P}}\right)$ shifted from 61.6 to $33.5^{\circ} \mathrm{C}$ when the percentage of FHRBO diminished from 90 to $10 \%$, respectively, a much more drastic decrease than that shown by the non-interesterified blends. This result is consistent with increased compatibility between the new TAG species in the products, as a consequence of the reduction of trisaturated TAG caused by interesterification, particularly StStSt, which has the highest melting point and very low solubility in the liquid oil.

\subsection{Solid fat content (SFC)}

The ratio between the amount of solid fat crystals and that of the liquid oil is determinant of fat plasticity and, additionally, influences the physical and sensory properties of an edible fat (Johnson, 2008). It is also well known that the texture and plasticity of a fatty material are strongly linked to SFC and with how this parameter varies with temperature (Lai et al., 1999).

Figure 4 shows the percentage of solid fat content (SFC) determined by RMN analysis as a function of temperature for the different blends RBO/FHRBO and their interesterification products.

While B-90 reached $0 \%$ SFC at $65^{\circ} \mathrm{C}, \mathrm{P}-90$ did at $60^{\circ} \mathrm{C}$, only $5{ }^{\circ} \mathrm{C}$ below the corresponding blend. The situation was different in samples with low percentages of FHRBO, while $0 \%$ SFC was achieved by $\mathrm{B}-10$ at $55^{\circ} \mathrm{C}$, the corresponding product $(\mathrm{P}-10)$ did at a temperature $20^{\circ} \mathrm{C}$ lower $\left(35^{\circ} \mathrm{C}\right)$. This result is coherent with the reduction of the concentration of the high melting point SSS molecular species as a consequence of the interesterification process, effect enhanced in products form blends with lower levels of FHRBO.

Results are in agreement too with the corresponding low variation in $T_{\mathrm{CB}}$ values determined by DSC analysis of the different blends. In contrast, $T_{\mathrm{CP}}$ values decreased drastically as the percentage of FHRBO diminished (Tab. 4).

A big difference can be observed in the variation of SFC of blends and products in the range from 10 to $25^{\circ} \mathrm{C}$, while blends 


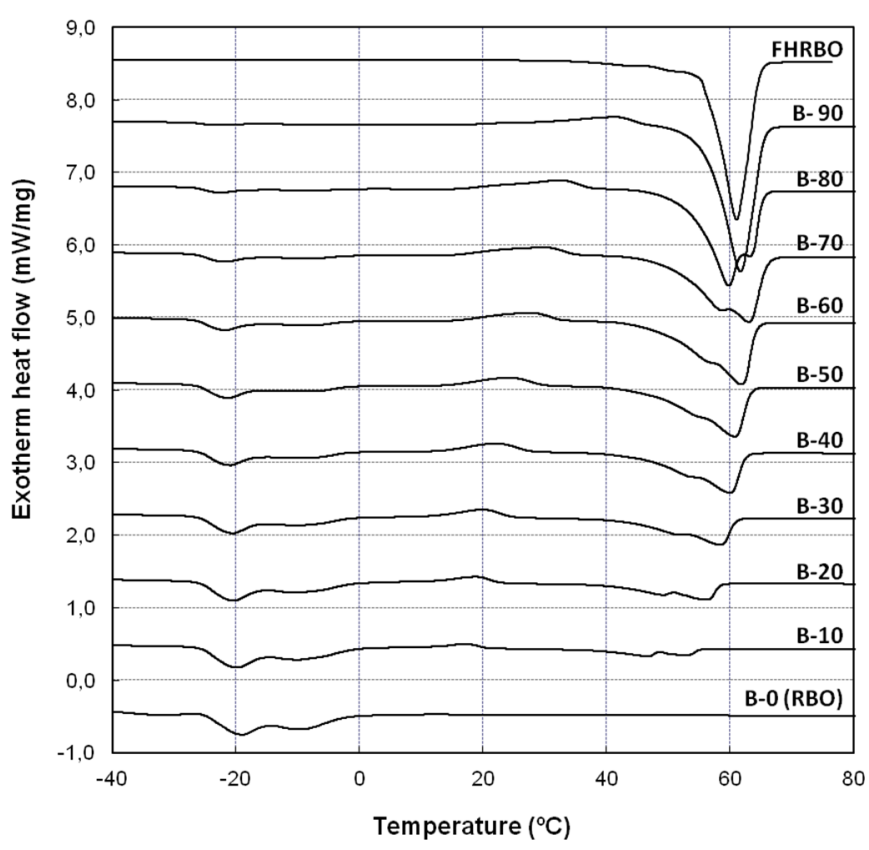

(a)

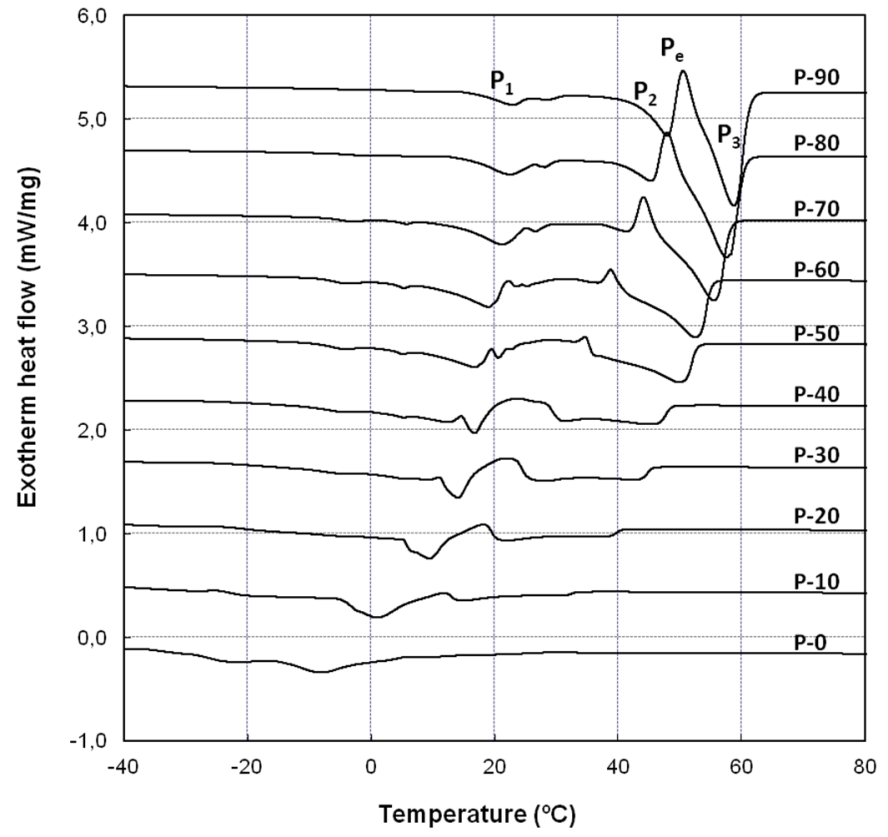

(b)

Fig. 3. Melting thermograms of the blends RBO/FHRBO at different proportions (a) and their interesterification products (b). Notes: "B-x": "Blend-\% FHRBO"; "P-y": "Product-\% FHRBO".

Table 4. Melting peak temperature $\left(T_{\mathrm{p}}\right)$ and completion melting temperature $\left(T_{\mathrm{c}}\right)$ of the different blends rice bran oil (RBO)/fully hydrogenated rice bran oil (FHRBO) and their interesterification products, determined from the melting thermograms obtained by DSC analysis (Fig. 3).

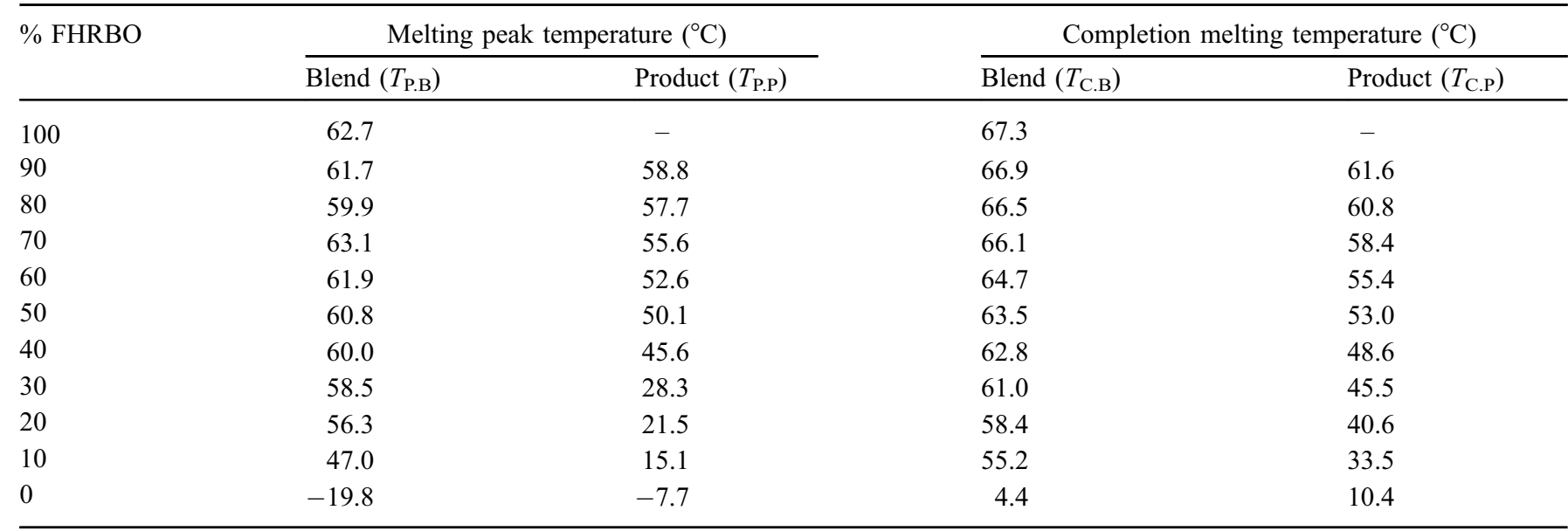

did not show high variations in SFC within these temperatures, products showed much lower SFC at 25 than at $10^{\circ} \mathrm{C}$. Such behaviour is important because it will involve a noticeable reduction in product hardness from refrigerator to room temperature.

It is interesting to analyze the solid fat content at $37^{\circ} \mathrm{C}$ $\left(\mathrm{SFC}_{37^{\circ} \mathrm{C}}\right)$ because of its influence on "mouth feel". According to Figure 4, products show a drastic reduction in $\mathrm{SFC}_{37{ }^{\circ} \mathrm{C}}$ as compared with the corresponding blends, which obviously is a direct consequence of the decrease in the concentration of high melting trisaturated TAG due to the interesterification (Fig. 2a). While B20, B30 and B40 had 16, 24 and 34\% solids at $37^{\circ} \mathrm{C}$, their corresponding products had 12,5 and $2 \%$ solids at the same temperature, respectively. Thus, these

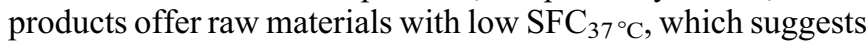
that undesired mouthfeel like waxiness, graininess or sandiness, should not be noted during their intake as food components.

SFC also provides information about the "plastic range" of a fat, defined as the temperature range over which it can be molded and spread, thus being neither too hard nor too soft. The sharpness of the melting range and other factors like crystal morphology determines the temperature range within which a fat could be considered plastic. As a reference, it has 


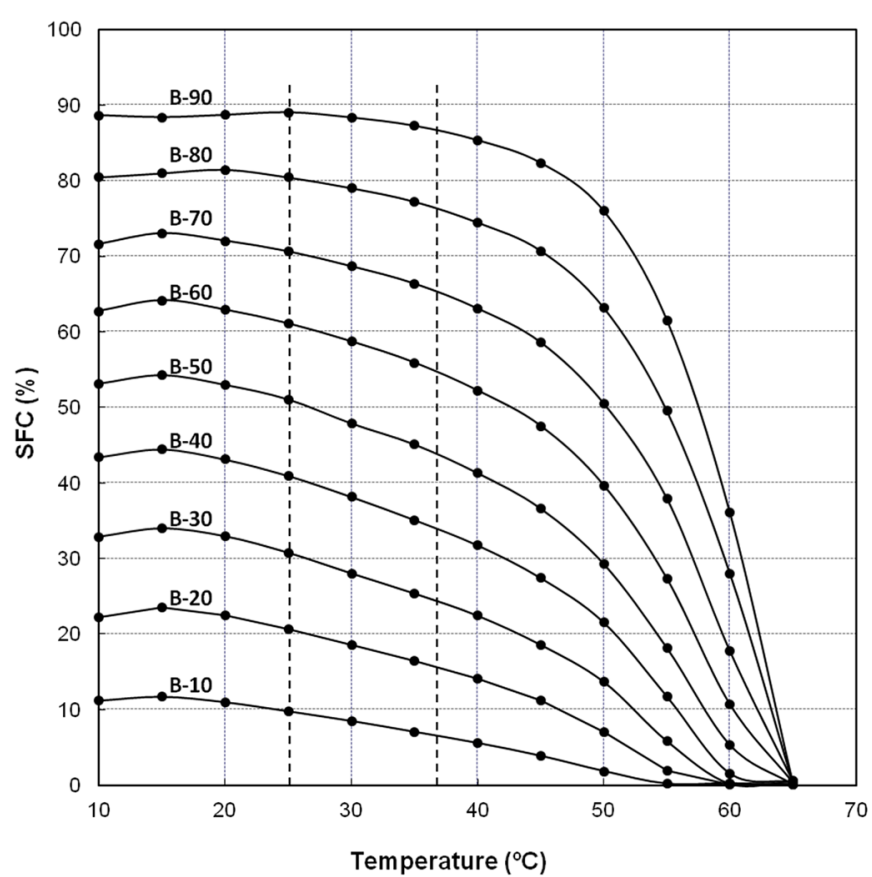

(a)

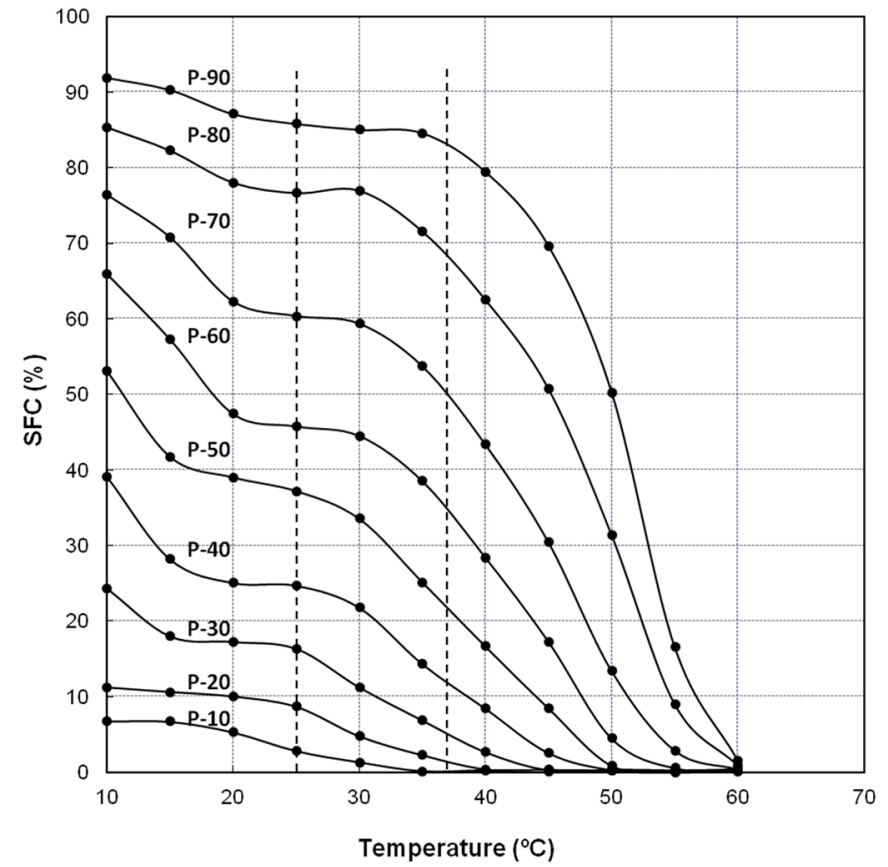

(b)

Fig. 4. Variation of solid fat content (SFC) with temperature for the blends RBO/FHRBO (a) and their interesterification products (b). Notes: "Bx": "Blend-\% FHRBO"; "P-y": "Product-\% FHRBO".

been considered that a convenient spreadability is achieved if SFC is within a range of roughly $15-35 \%$, and temperatures corresponding to both SFC limits defined the plastic range of a fat (DeMan, 1992).

Figure $4 \mathrm{~b}$ shows that $\mathrm{P}-50$ matches such requirement from about 30 to $40^{\circ} \mathrm{C}$, thus surely being too hard at temperatures over room temperature. Conversely, P-30 had a SFC high enough to be considered plastic at temperatures below $25^{\circ} \mathrm{C}$, while over this temperature, SFC falls below the minimum of $15 \%$ required. Thus, $\mathrm{P}-40$ appears as the more suitable material in terms of plasticity, with a plastic range from 12 to $35^{\circ} \mathrm{C}$, which covers the widest temperature range containing room temperature.

\subsection{Polymorphism}

The diffractogram of pure FHRBO in the short spacing region shows two strong diffraction peaks at 3.8 and $4.2 \AA$ (Fig. 5a), which indicates that the crystallization of the sample generated the $\beta$ ' polymorph. This result is highly promising considering that this is the more convenient polymorph for the products of interest and the absence of any other diffraction peaks corresponding to polymorphic forms different from $\beta$ '. It is well known that the existence or non-existence of a polymorph depends heavily on the composition and the position of the fatty acids on the glycerol unit (Foubert et al., 2007).

X-ray diffraction analysis confirmed that the percentage of palmitic acid in FHRBO confers to this fat a heterogeneity high enough to generate a stable $\beta$ ' polymorph. Thus, although FHRBO contains $50.6 \%$ of the $\beta$-tending StStSt, the presence of two known $\beta$ '-tending TAGs, PStSt and PStP (Timms, 2003), totalizing $49.7 \%$, was enough to promote $\beta$, crystallization. This result is in agreement too with the fact that $\beta^{\prime}$-polymorph is usually the most stable one if the triglyceride is asymmetrical (Foubert et al., 2007), like PStSt.

The situation changed as the percentage of RBO was progressively increased in the blends. As shown in Figure 5a, the diffraction peak at $4,6 \AA$ corresponding to $\beta$ polymorph appeared when B- 80 was analyzed, accompanied by the relative diminishing in the intensity of peaks corresponding to $\beta$ ' polymorph. As RBO percentage increased from B-80 to B-20, the relative intensity of peaks changed, suggesting an increasing ratio from $\beta$ to $\beta$ ' polymorph. Results can be explained considering that the heterogeneous $\beta$ '-tending TAGs from FHRBO are more soluble than StStSt in the liquid RBO, thus, as the proportion of RBO increased, the proportion of StStSt in the solid fraction increased too, conferring to the blend a higher preference to crystallize in the $\beta$ form.

Concerning the interesterification products (Fig. 5b), the diffractogram of P-80 shows, like that of B-80, peaks indicating the presence of both $\beta$ and $\beta$ ' polymorphs in their solid fraction. But, unlike B-60, the P-60 diffractogram shows only the peaks corresponding to $\beta$ ' polymorph. Such behaviour can be associated with the reduction in the concentration of StStSt from $30.4 \%$ in M-60 to only $9.3 \%$ in P-60. Additionally, the overall TAG composition of products is much more heterogeneous than that of the original blend, which can also contribute to enhancing the $\beta$ ' tendency of the products.

\section{Conclusions}

Results showed that the relatively high content of palmitic acid in rice bran oil was enough to confer the required heterogeneity to triacylglycerols to promote the crystallization 


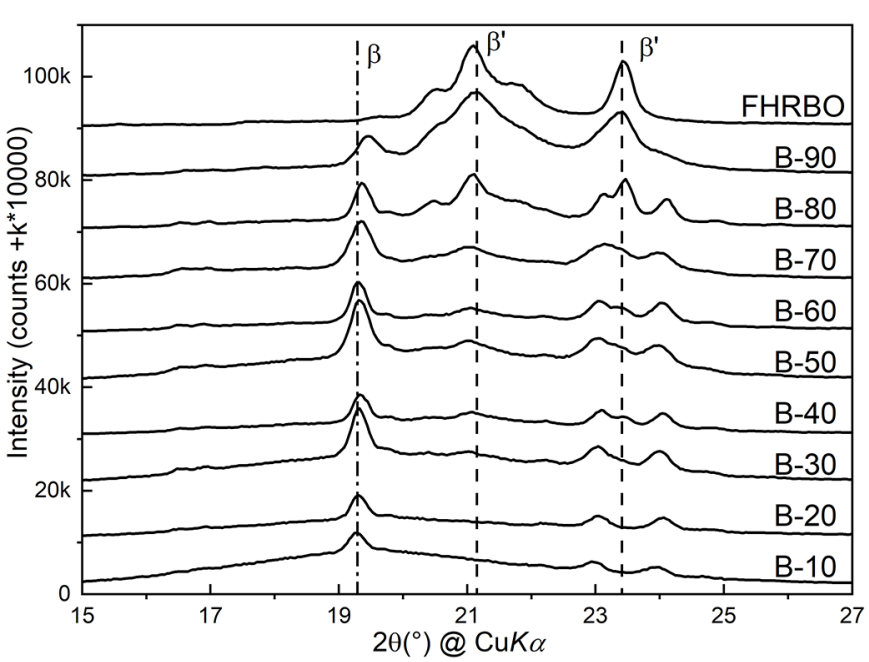

(a)

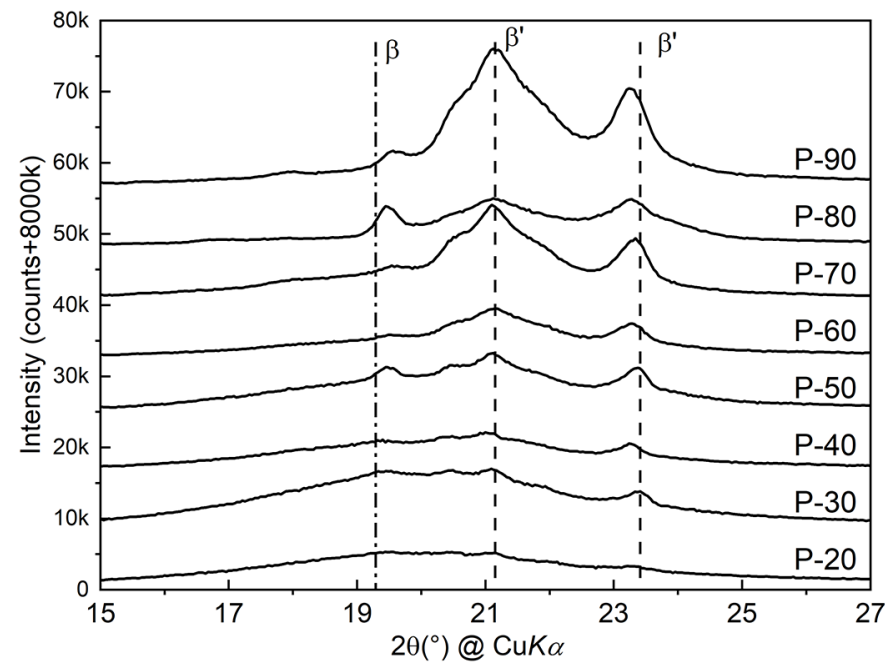

(b)

Fig. 5. Powder X-ray diffraction patterns collected at $20^{\circ} \mathrm{C}$ for the blends RBO/FHRBO (a) and their interesterification products (b).

of the fully hydrogenated oil in the $\beta$ ' form. Additionally, this polymorphic form was also predominant in the interesterification products, a valuable property in fats destined for edible applications. Conversely to the low compatibility showed by the trisaturated and triunsaturated TAGs provided by both components to the blends, the interesterification process produced new TAGs species with an intermediate unsaturation degree and improved compatibility. These changes impacted on the thermal behaviour of the products, reducing their melting point and solid fat content. Thus, by conveniently choosing the proportion of each component in the starting blend, it is feasible to design products with different properties according to that required by the edible application to be destined.

Results demonstrated that the proposed methodology involving fully hydrogenation, blending, and interesterification offers a valuable tool for producing zero-trans products using solely RBO as the starting raw material, which could diversify the utilization of a valuable vegetable oil still underexploited.
Acknowledgments. The authors thank to CSIC (Comisión Sectorial de Investigación Científica, Universidad de la República), PEDECIBA (Programa de Desarrollo de las Ciencias Básicas), CAP (Comisión Académica de Posgrado, Universidad de la República), ANII (Agencia Nacional de Investigación e Innovación) for the financial support and scholarships.

\section{References}

American Oil Chemists' Society (AOCS). 2017. Official methods and recommended practices of the American Oil Chemists' Society, 7th ed. In: Firestone D, ed. Champaign, IL: American Oil Chemists' Society.

Chandrashekar P, Kumar PKP, Ramesh HP, Lokesh BR, Krishna AGG. 2014. Hypolipidemic effect of oryzanol concentrate and low temperature extracted crude rice bran oil in experimental male Wistar rats. J Food Sci Technol 51: 1278-1285. https://doi. org/10.1007/s13197-012-0628-9.

Chung SI, Kang MY. 2020. A study on the functional components and health effectiveness of germinated Oryza sativa L. "Superhongmi”. J Crop Sci Biotech 23(5): 483-490. https://doi.org/ 10.1007/s12892-020-00068-z.

Danthine S, Lefébure E, Trinh HN, Blecker C. 2014. Effect of palm oil enzymatic interesterification on physicochemical and structural properties of mixed fat blends. J Am Oil Chem Soc 91(9): 1477-1487. https://doi.org/10.1007/s11746-014-2494-2.

DeMan JM. 1992. Fats and oils: chemistry, physics and applications. In: Hui HD, ed. Encyclopedia of food science and technology. New York: John Wiley \& Sons, pp. 823-824.

Di Rienzo JA, Casanoves F, Balzarini MG, González L, Tablada M, Robledo CW. 2020. InfoStat, version 2020. Argentina: Universidad Nacional de Córdoba. http://www.infostat.com.ar.

Feltes MMC, de Oliveira D, Block JM, Ninow JL. 2012. The production, benefits, and applications of monoacylglycerols and diacylglycerols of nutritional interest. Food Bioproc Technol 6: 17-35. https://doi.org/10.1007/s11947-012-0836-3.

Firestone D. 2006. Physical and chemical characteristics of oils, fats, and waxes, 2nd ed. Champaign: AOCS Press.

Foubert I, Dewettinck K, Van de Walle D, Dijkstra AJ, Quinn PJ. 2007. Physical properties: structural and physical characteristics. In: Gunstone FD, Harwood JL, Dijkstra AJ, eds. The lipid handbook, 3rd ed. Boca Raton: Taylor \& Francis Group, CRC Press, pp. 471-509.

Jahaniaval F, Kakuda Y, Abraham V. 2002. Oil-binding capacity of plastic fats: effects of intermediate melting point TAG. J Am Oil Chem Soc 79: 389-394. https://doi.org/10.1007/s11746-0020494-6.

Jennings BH, Akoh CC. 2010. Trans-free plastic shortenings prepared with palm stearin and rice bran oil structured lipid. J Am Oil Chem Soc 87(4): 411-417. https://doi.org/10.1007/s11746-009-1516-y.

Jiang Y. 2019. Bioprocessing technology of rice bran oil. In: Xu X, Cheong LZ, eds. Rice bran and rice bran oil: chemistry, processing and utilization, 1st ed. Academic Press and AOCS Press, pp. 97-123.

Johnson LA. 2008. Recovery, refining, converting, and stabilizing edible fats and oils. In: Akoh CC, Min DB, eds. Food lipids chemistry, nutrition and biotechnology, 3rd ed. Boca Raton, USA: CRC Press, pp. 206-241.

Kloek W, Walstra P, Van Vliet T. 2000. Crystallization kinetics of fully hydrogenated palm oil in sunflower oil mixtures. $J$ Am Oil Chem Soc 77(4): 389-398. https://doi.org/10.1007/s11746-0000063-z. 
Kodali DR. 2005. Trans fats-chemistry, occurrence, functional need in foods and potential solutions. In Kodali DR, List GR, eds.Trans fat alternatives, 1st ed. AOCS Press, pp. 1-25.

Lai OM, Ghazali HM, Let CC. 1999. Use of enzymatic transesterified palm stearin-sunflower oil blends in preparation of table margarine formulation. Food Chem 64(1): 83-88. https://doi. org/10.1016/S0308-8146(98)00083-1.

Li Y, Zhao J, Xie X, Zhang Z, Zhang N, Wang Y. 2018. A low trans margarine fat analog to beef tallow for healthier formulations: optimization of enzymatic interesterification using soybean oil and fully hydrogenated palm oil. Food Chem 255: 405-413. https://doi.org/10.1016/j.foodchem.2018.02.086.

Liu R, Xu Y, Chang M, et al. 2021. Antioxidant interaction of $\alpha$-tocopherol, $\gamma$-oryzanol and phytosterol in rice bran oil. Food Chem 343: 128431. https://doi.org/10.1016/j.foodchem.2020.128431.

Mayamol PN, Balachandran C, Samuel T, Sundaresan A, Arumughan C. 2009. Zero trans shortening using rice bran oil, palm oil and palm stearin through interesterification at pilot scale. Int J Food Sci Tech 44: 18-28. https://doi.org/10.1111/j.1365-2621.2008.01627.x.

Oi-Ming L, Jörg JJ, Wai-Fun L, Wee-Ting L. 2019. Nutritional studies of rice bran oil. In: Xu X, Cheong LZ, eds. Rice bran and rice bran oil: chemistry, processing and utilization, 1st ed. Academic Press and AOCS Press, pp. 19-54.

Oteng AB, Kersten S. 2020. Mechanisms of action of trans fatty acids. Adv Nutr 11: 697-708. https://doi.org/10.1093/advances/nmz125.

Pacheco C, Palla C, Crapiste GH, Carrín ME. 2013. Optimization of reaction conditions in the enzymatic interesterification of soybean oil and fully hydrogenated soybean oil to produce plastic fats. J Am Oil Chem Soc 90(3): 391-400. https://doi.org/10.1007/ s11746-012-2182-z.

Ribeiro AP, Grimaldi R, Gioielli LA, Gonçalves L. 2009. Zero trans fats from soybean oil and fully hydrogenated soybean oil: physico-chemical properties and food applications. Food Res Int 42(3): 401-410. https://doi.org/10.1016/j.foodres.2009.01.012.

Sato K. 2001.Molecular aspects in fat polymorphism. In: Wildlak N, Hartel R, eds. Crystallization and solidification properties of lipids. Champaign, Illinois: AOCS Press, pp. 1-17.

Segura N, Da Silva R, Schäfer F, Gioielli LA, Jachmanián I. 2011, Valorization of beef tallow by lipase-catalyzed interesterification with high oleic sunflower oil. J Am Oil Chem Soc 88: 1945-1954. https://doi.org/10.1007/s11746-011-1876-y.

Segura N, Jachmanián I. 2020. Zero-trans fats by enzymatic interesterification of blends beef tallow/rice bran oil. Oil Crops Lipids 27: 4. https://doi.org/10.1051/ocl/2019052.

Shi Y, Liang B, Hartel RW. 2005. Crystal morphology, microstructure, and textural properties of model lipid system. J Am Oil Chem Soc 82(6): 399-408. https://doi.org/10.1007/s11746-0051084-3.

Timms RE. 2003. Confectionery fats handbook: properties, production and application (chapter 2). Bridgwater, UK: The Oily Press.

World Health Organization (WHO). 2018. RAPLACE trans fat: an action package to eliminate industrially-produced trans fat from the global food supply. https://www.who.int/teams/nutrition-andfood-safety/replace-trans-fat.

Xu Z, Hua N, Godber S. 2001. Antioxidant activity of tocopherols, tocotrienols, and $\gamma$-oryzanol components from rice bran against cholesterol oxidation accelerated by 2, 2'-Azobis(2-methylpropionamidine) Dihydrochloride. J Agric Food Chem 49(4): 2077-2081. https://doi.org/10.1021/jf0012852.

Zhang D, Duan X, Wang Y, et al. 2021. A comparative investigation on physicochemical properties, chemical composition, and in vitro antioxidant activities of rice bran oils from different japonica rice (Oryza sativa L.) varieties. Food Meas 15: 2064-2077. https://doi.org/10.1007/s11694-020-00806-5.

Cite this article as: Callejas Campioni N, Suescun Pereyra L, Badan Ribeiro AP, Jachmanián Alpuy I. 2021. Zero-trans fats designed by enzyme-catalyzed interesterification of rice bran oil and fully hydrogenated rice bran oil. OCL 28: 46. 